\title{
Aerobic and anaerobic arm-cranking power outputs of males with lower limb impairments: Relationship with sport participation intensity, age, impairment and functional classification
}

\author{
Yeshayahu Hutzler ${ }^{1}$, Shai Ochana ${ }^{1}$, Ron Bolotin ${ }^{2}$ and Eliezer Kalina ${ }^{2}$ \\ ${ }^{1}$ The Zinman College for Physical Education and Sports Sciences, Wingate Institute, Israel 42902; ${ }^{2}$ Israeli Defence \\ Force Veteran Sports and Rehabilitation Center, Netania, Israel 42902
}

\begin{abstract}
Fifty individuals with lower limb impairments including spinal cord injury, polio and amputations underwent aerobic and anaerobic arm-cranking tests in a standardized laboratory setting. Based on linear regression models applied with age as dependent variable aerobic performance variable including $\operatorname{HRmax}(R=0.395, P=0.004)$, and POaer $(R=0.31, P=0.021)$ were subjected to ANCOVA adjusting for age in order to determine the significance of participation intensity (competitive vs leisure) and type of physical impairment. Anaerobic performance variables were not influenced by age and thereby subjected to 1-Way ANOVA with the same independent variables. Participation intensity and type of impairment significantly discriminated $(P<0.001)$ between athletes in all power variables. Linear regression models have shown moderate but significant $(P<0.001)$ relationship with functional ability (bases on International Wheelchair Basketball Federation classification system). In anaerobic mean power (MP) classification accounted for $42 \%$ of the variance, while in anaerobic peak power (PP) and aerobic Power (POaer) for 38\% and 30\% respectively. By means of a post hoc Tukey analysis significant differences were observed between athletes with a high level paraplegia (class 1) and those with one leg affected by polio or amputations (classes 4, 4.5). Athletes with low level paraplegia and two legs affected by polio (classes $2-$ 3.5) had values in-between. Based on the descriptive evaluation, a three group scheme was conceptualized and resubjected to ANOVA. Significant intergroup differences were thus obtained only for PP. Descriptive PP data for each group were transformed into a five category table in order to provide reference values for fitness estimation in males with lower limb impairments of various etiologies.
\end{abstract}

Keywords: physical fitness; arm-cranking ergometry; lower limb impairments; spinal cord injury; physical activity; classification

\section{Introduction}

Arm crank exercise has always been the most popular method for fitness evaluation in individuals with lower limb disabilities. ${ }^{1,2}$ ). It was utilized in several classic studies $^{3-5}$ and is still the major component in designing large scale cross sectional studies. ${ }^{6}$ Apart of its low cost and portability, it is also considered a skillfree stressor for the cardio-respiratory and muscular systems and thus relatively invulnerable to measurement bias deriving from personal levels of skill acquisition and motivation. ${ }^{1}$ Latter characteristic could, eventually, be interpreted as a disadvantage referring to the dissimilarities existing between arm cranking and the major physical activity performed by individuals with lower limb impairments, namely actual wheelchair propulsion. ${ }^{2}$ Arm cranking exercise seems

Correspondence: Yeshayahu Hutzler, Ph.D. to be an appropriate method for assessment of individuals who do not mobilize themselves by means of manual wheelchair propulsion, but rather via prothetically or orthoticly aided ambulation. In the case of sports, if the relevant performance includes non-specific activities such as swimming, weight-lifting or fencing, arm crank exercise is more suitable for comparative assessment than wheelchair specific exercise modalities such as wheelchair ergometry. Following the recent functional sport classification reform individuals with paraplegia do not compete among themselves anymore. Instead, they are being integrated together with individuals with amputations and other orthopedic impairments into the same competition categories. ${ }^{7-9}$ The criteria for classification have also been changed into a functional sport based model $^{10}$ rather than a medical impairment model. Following this reform, the question raises 
whether the fitness level of athletes with paraplegia is comparable with that of athletes with other lower limb impairments. Previous studies have predominantly assessed cardio-respiratory fitness of spinal cord injured collectives with particular respect to differences in their lesion level (for reviews $s^{2} e^{2,11}$ ). Maximal power outputs obtained during graded aerobic armcrank testing have shown good relationship with VO2peak and other cardiorespiratory variables. ${ }^{12}$ The first goal of this study is therefore, to compare power outputs of individuals with various reasons for a lower limb disability with respect to their functional classification level.

Several studies have described both aerobic and anaerobic performance variables of individuals with spinal cord lesion on a wheelchair ergometer, ${ }^{13,14}$ but only a few studies were conducted to date with armcranking ergometers in order to assess anaerobic performance of individuals with lower limb impairments. ${ }^{14-17}$ This seems particularly justified, taking into account the short duration and relatively high stress of many daily and sport related activities conducted by individuals with lower limb impairments. ${ }^{18,19}$ Thus, the second goal of this study is to provide reference values in both aerobic and anaerobic performance.

Previous attempts to study the relationship of participation in regular physical activity with performance of the cardio-respiratory system ${ }^{2,4,5,20}$ and anaerobic performance ${ }^{21}$ have not included age as a potential biasing factor. Neither has age been considered as a possible distracter in statistical analyses revealing differences in aerobic and anaerobic performance between groups of individuals with different classification. ${ }^{14,21,22}$ In one study ${ }^{23}$ authors have used a cross-sectional design and reported a decline in aerobic capacity by age for individuals with spinal cord injuries that was similar to the decline observed in able-bodied population. ${ }^{24}$ The third goal of this study is therefore to control for age in evaluating the relationship of participation in sports and classification on aerobic and anaerobic performance of individuals with lower limb impairments.

\section{Methods}

\section{Subjects}

Fifty male individuals with lower limb impairments were recruited to participate in this study after completing a written consent. Ten participated occasionally (1-2 sessions a week) in leisure time sport activities, particularly recreational swimming and table tennis. They comprised the leisure activity group. The remaining 40 were competitive athletes specializing in different sport disciplines of national and international level and were involved in vigorous training (35 weekly sessions) including structured training in their main discipline and complementary exercise sessions. They comprised the competitive sport group. All participants were divided among four disability groups according to their type and level of impairment. Thirteen individuals had high Paraplegia (complete above T6). Fifteeen had low Paraplegia (complete or incomplete below T6 to S5). Discrimination between high and low paraplegia was based on the anatomical cut-off level II to III utilized by the International Stoke Mandeville Games Federation (ISMGF) for classification of spinal injuries. ${ }^{2}$ Ten had above knee or below knee unilateral amputations and 12 had a postpoliomyelitic lower limb lesion. Since a considerable number of subjects were predominantly engaged with wheelchair basketball (Table 1), a scheme was used to determine the functional classification system that is currently in international use for wheelchair basketball. $^{7}$ This procedure includes eight levels starting from 1 point (severe paralysis of the lower limbs and trunk resulting in the least function available for playing wheelchair basketball) reaching up to 4.5 points (minimal disability resulting in maximal functional ability comparable to an able bodied) with half point intervals in between. All subjects were classified by approved international or national experts. Athlete's distribution among classes was about normal, with 13 classified as 1 point, two as 1.5 points, 13 as 2 points, one as 2.5 points, four as 3 points, one as 3.5 points, six as 4 points and ten as 4.5 points. Athletes included in the leisure group were equally divided among the 1 point and 2 point classes (five athletes in each class). Therefore the significance of activity intensity will be restricted to these categories only.

\section{Instrumentation and procedure}

Each subject visited the sports medicine laboratory on two different days with a 7-14 days interval inbetween. Each of the testing sessions, included either the anaerobic or the aerobic ergometer test protocols. Both sessions were performed under sports medical supervision and were using the same arm cranking device (Fleish Metabo: Basel, Switzerland). Prior to completion of both tests athletes were interviewed for their sport history and anthropometric measurements were obtained, including weight and fat \% (based on subscapular, suprailliac and triceps skin folds measured via caliper). The first test was a modified Wingate Anaerobic Test protocol (WAnT: 25) adapted for arm use. $^{16,26}$ This is a reliable all-out $30 \mathrm{~s}$ arm-cranking test

Table 1 Number of subjects by main sport event

\begin{tabular}{lr}
\hline Main sport event & $n$ \\
\hline Wheelchair basketball & 22 \\
Track & 2 \\
Swimming & 6 \\
Volleyball & 4 \\
Table tennis & 3 \\
Weightlifting & 3 \\
Leisure activities & 10 \\
\hline
\end{tabular}


measuring Peak Anaerobic PO in a $5 \mathrm{~s}$ interval (PP), Mean Anaerobic Capacity, which is the mean PO over the whole $30 \mathrm{~s}$ period (MP) and Fatigue Index (FI), which is the percentage of PP achieved during the last $5 \mathrm{~s}$ interval. The resistance was determined relative to body weight at $35 \mathrm{~g} / \mathrm{kg}^{27}$ The second test was a graded exercise loading to exhaustion protocol (240 g increments starting with $240 \mathrm{~g}$ and lasting $2 \mathrm{~min}$ each). Cranking rate was set at $70 \mathrm{rpm}$. Peak aerobic power output (POaer) was recorded during the graded exercise. HR was continuously measured by means of EKG to control for pathological symptoms. Reliability and validity of arm cranking for the measurement of aerobic and anaerobic performance were established previously $^{28,29}$ respectively.

Statistical analyses were carried out by means of SPSS and included: (a) product moment correlation and linear regression models among the $\mathrm{PO}$ variables and with age (b) ANCOVA adjusting for age with PO variables significantly correlating with age; (c) 1-Way ANOVA with Tukey HSD post hoc tests among activity intensity and impairment groups.

\section{Results}

The mean age in the present sample was relative high for athletes $(38.9 \pm 9.2)$ with a range between 18 and 62 years. The mean values of the competitive and leisure group $(38.1 \pm 8.79$ and $41.9 \pm 10.70)$ were analyzed by means of 1-way ANOVA and did not differ significantly from each other $(\mathrm{F}[1,24]=9.85, P=0.11)$. Linear regression models applied with age as the independent variable found moderate significant negative relationships with $\mathrm{HRmax}(R=-0.395$, $P=0.004)$, and POaer $(R=0.31, \quad P=0.021)$. No significant relationship were found with the other $\mathrm{PO}$ variables.

Table 2 presents mean values and SD of the dependent variables for the leisure and competitive groups separately.

These results clearly demonstrate the impact of activity intensity on PO in athletes with paraplegia. The descriptive data was confirmed by means of an ANCOVA with age being the covariant and activity intensity the independent variable (Table 3). This analysis revealed that activity intensity significantly explained the variance in all PO variables among individuals with lower limb impairments. During the ANCOVA applied on aerobic power output variables with impairment as independent variable, age was found having a significant impact on POaer $(\mathrm{F}[1,48]=5.25, \quad P=0.027) \quad$ and on HRmax $(\mathrm{F}[1,48]=8.03, P=0.007)$. Type of impairment had a significant impact on POaer but not on HRmax. 1Way ANOVA revealed significant impact of impairment on all anaerobic power output variables (Table 3).

The means and SD of the four impairment groups are demonstrated in Figure 1. Groups include individuals with: (a) high level paraplegia (above T6 complete); (b) low level paraplegia (below T6 complete or equivalent); (c) polio; and (d) lower limb amputations. A visual analysis of Figure 1 clearly demonstrated differences among power outputs of groups $\mathrm{a}$ and $\mathrm{d}$ and similarities between groups $\mathrm{b}$ and $\mathrm{c}$ which seemed to comprise together an intermediate group between a and $\mathrm{d}$.

Tukey range HSD significantly discriminated between athletes with either high level or low level paraplegia (groups a and b respectively) and athletes with amputations (group d) in all PO variables. In FI individuals with high level lesions (group a) differed significantly from athletes with amputations (group d) and those with polio (group c).

Table 3 ANCOVA, 1-Way ANOVA and post hoc intergroup differences by impairment. $\mathrm{F}$ values and significance level in parentheses

\begin{tabular}{lcrcc}
\hline $\begin{array}{l}\text { Dependent } \\
\text { variable }\end{array}$ & \multicolumn{1}{c}{ ANCOVA } & \multicolumn{1}{c}{$\begin{array}{c}\text { 1-Way } \\
(P)\end{array}$} & \multicolumn{1}{c}{$\begin{array}{c}\text { ANOVA } \\
(P)\end{array}$} & $\begin{array}{c}\text { Between group } \\
(\text { Alpha }<0.005)\end{array}$ \\
\hline $\mathrm{PO}_{\mathrm{aer}}$ & $7.57(0.00)$ & $5.79(0.002)$ & $\mathrm{a}, \mathrm{b}<\mathrm{d}$ \\
$\mathrm{HR}$ & $0.15(0.92)$ & $0.15(0.92)$ & \\
$\mathrm{MP}$ & $10.86(0.00)$ & $11.90(0.000)$ & $\mathrm{a}<\mathrm{c}, \mathrm{d} ; \mathrm{b}<\mathrm{d}$ \\
$\mathrm{PP}$ & $10.92(0.00)$ & $12.01(0.000)$ & $\mathrm{a}<\mathrm{c}, \mathrm{d} ; \mathrm{b}<\mathrm{d}$ \\
$\mathrm{FI}$ & $3.75(0.01)$ & $3.57(0.021)$ & $\mathrm{a}<\mathrm{d}$ \\
\hline
\end{tabular}

Table 2 Mean and SD (in parenthesis) of dependent variables obtained in the study by activity and impairment group

\begin{tabular}{|c|c|c|c|c|c|c|c|}
\hline $\begin{array}{l}\text { Group } \\
\text { variable }\end{array}$ & $\begin{array}{l}\text { h.l.Para } \\
\text { leisure }\end{array}$ & $\begin{array}{l}\text { h.l.Para } \\
\text { compete }\end{array}$ & $\begin{array}{l}\text { l.l.Para } \\
\text { leisure }\end{array}$ & $\begin{array}{l}\text { l.l.Para } \\
\text { compete }\end{array}$ & $\begin{array}{c}\text { Polio } \\
\text { compete }\end{array}$ & $\begin{array}{c}\text { Amputees } \\
\text { compete }\end{array}$ & $\begin{array}{c}\text { All } \\
\text { Athletes }\end{array}$ \\
\hline $\mathrm{HR}_{\max }\left(\right.$ beats $\left.^{*} \min ^{-1}\right)$ & $\begin{array}{l}165.00 \\
(12.12)\end{array}$ & $\begin{array}{l}179.75 \\
(16.71)\end{array}$ & $\begin{array}{l}176.50 \\
(10.69)\end{array}$ & $\begin{array}{l}171.14 \\
(21.00)\end{array}$ & $\begin{array}{l}170.83 \\
(18.48)\end{array}$ & $\begin{array}{l}173.92 \\
(13.92)\end{array}$ & $\begin{array}{l}173.47 \\
(16.52)\end{array}$ \\
\hline POaer (Watts) & $\begin{array}{c}79.00 \\
(18.29)\end{array}$ & $\begin{array}{c}97.57 \\
(23.10)\end{array}$ & $\begin{array}{c}88.67 \\
(13.98)\end{array}$ & $\begin{array}{l}124.44 \\
(40.54)\end{array}$ & $\begin{array}{l}129.63 \\
(23.55)\end{array}$ & $\begin{array}{c}147.08 \\
(37.79)\end{array}$ & $\begin{array}{l}118.52 \\
(38.32)\end{array}$ \\
\hline MP (Watts) & $\begin{array}{l}239.25 \\
(76.22)\end{array}$ & $\begin{array}{l}279.51 \\
(80.38)\end{array}$ & $\begin{array}{l}256.17 \\
(64.45)\end{array}$ & $\begin{array}{l}335.63 \\
(39.91)\end{array}$ & $\begin{array}{c}394.48 \\
(101.07)\end{array}$ & $\begin{array}{l}442.80 \\
(97.78)\end{array}$ & $\begin{array}{c}341.12 \\
(102.48)\end{array}$ \\
\hline PP (Watts) & $\begin{array}{l}306.00 \\
(66.27)\end{array}$ & $\begin{array}{l}342.85 \\
(95.21)\end{array}$ & $\begin{array}{l}348.33 \\
(52.91)\end{array}$ & $\begin{array}{l}439.54 \\
(66.31)\end{array}$ & $\begin{array}{l}459.26 \\
(91.24)\end{array}$ & $\begin{array}{c}542.05 \\
(108.80)\end{array}$ & $\begin{array}{c}428.86 \\
(114.50)\end{array}$ \\
\hline FI $(\%)$ & $\begin{array}{c}58.00 \\
(22.46)\end{array}$ & $\begin{array}{c}55.00 \\
(15.15)\end{array}$ & $\begin{array}{c}49.50 \\
(17.10)\end{array}$ & $\begin{array}{c}45.79 \\
(14.25)\end{array}$ & $\begin{array}{c}34.25 \\
(10.44)\end{array}$ & $\begin{array}{c}39.00 \\
(14.80)\end{array}$ & $\begin{array}{c}46.29 \\
(16.47)\end{array}$ \\
\hline
\end{tabular}




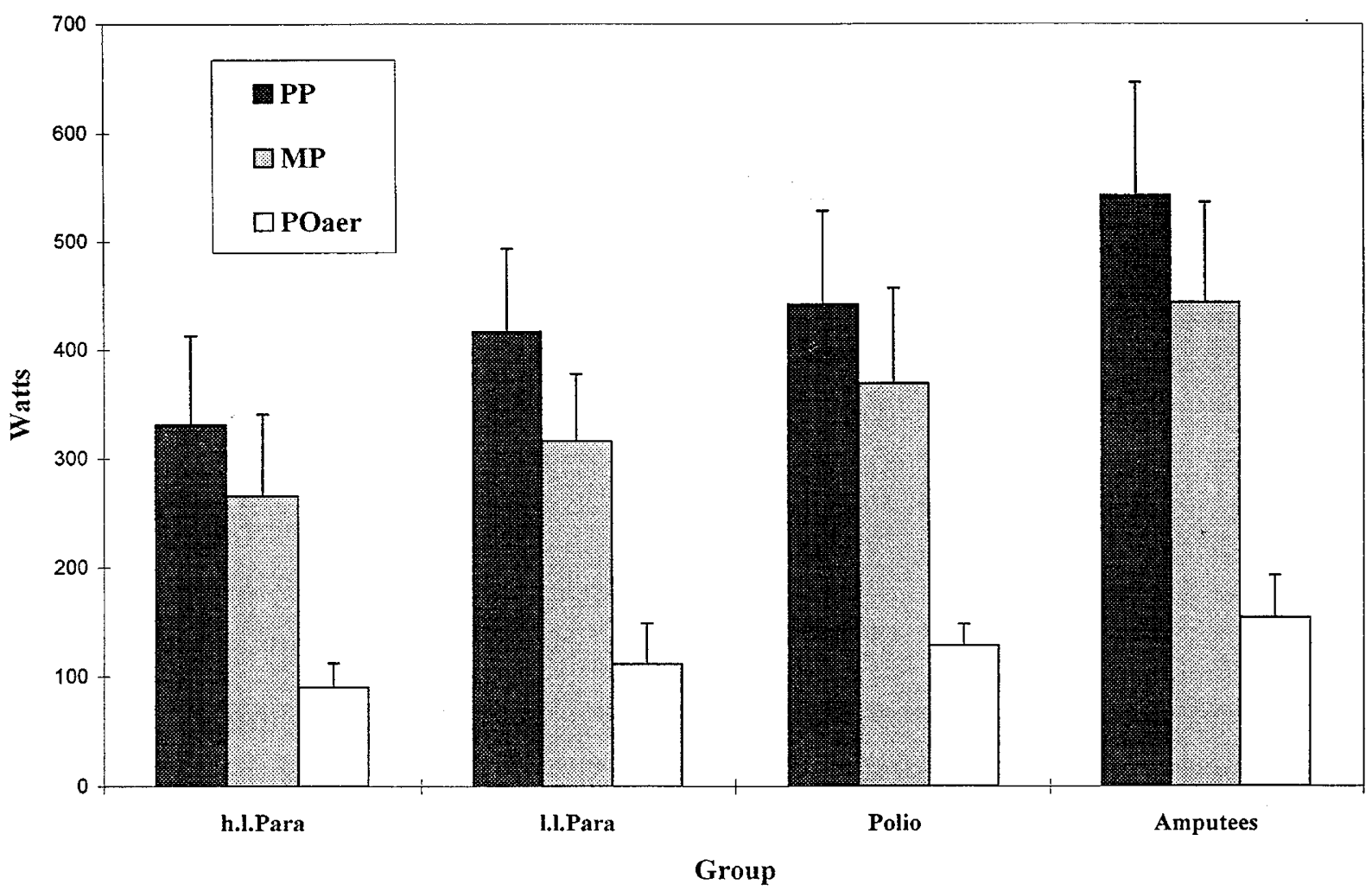

Figure 1 Power outputs of subjects in different impairment groups

Table 4 1-Way ANOVA and post hoc intergroup differences by the revised three group model in all subjects and competitive athletes only

\begin{tabular}{|c|c|c|c|c|}
\hline \multirow[b]{2}{*}{$\begin{array}{l}\text { Dependent } \\
\text { variable }\end{array}$} & \multicolumn{2}{|c|}{ All subjects $(n=50)$} & \multicolumn{2}{|c|}{ Competitive athletes $(n-40)$} \\
\hline & $\begin{array}{cc}1-\text { Way } & A N O V A \\
F & (P)\end{array}$ & $\begin{array}{l}\text { Between group } \\
(\text { Alpha }<0.05)\end{array}$ & $\begin{array}{cc}1-W a y & A N O V A \\
F & (P)\end{array}$ & $\begin{array}{l}\text { Between group } \\
(\text { Alpha }<0.05)\end{array}$ \\
\hline $\mathrm{PO}_{\mathrm{aer}}$ & $8.11(0.001)$ & $\mathrm{a}, \mathrm{b}<\mathrm{c}$ & $4.6(0.017)$ & $\mathrm{a}, \mathrm{b}<\mathrm{c}$ \\
\hline MP & $14.6(0.000)$ & $\mathrm{a}, \mathrm{b}<\mathrm{c}$ & $10.8(0.0002)$ & $\mathrm{a}, \mathrm{b}<\mathrm{c}$ \\
\hline PP & $17.4(0.000)$ & $\mathrm{a}<\mathrm{b}, \mathrm{c} ; \mathrm{b}<\mathrm{c}$ & $12.2(0.0001)$ & $\mathrm{a}<\mathrm{b}, \mathrm{c} ; \mathrm{b}<\mathrm{c}$ \\
\hline FI & $4.09(0.02)$ & $\mathrm{a}<\mathrm{c}$ & $3.28(0.05)$ & $\mathrm{a}<\mathrm{c}$ \\
\hline
\end{tabular}

Based on the visual analysis and the post hoc analysis we clustered groups $\mathrm{b}$ and $\mathrm{c}$ together and applied 1-Way ANOVA and Tukey HSD procedures to discriminate between groups. We thus found that the combined $\mathrm{b}+\mathrm{c}$ group (subjects with low level paraplegia or polio) differed significantly $(P<0.05)$ from both other groups with respect to anaerobic PP $(\mathrm{F}[2,48]=17.4, P=0.000)$. With respect to the other variables (MP, POaer) it did not differ from group a (h.l. paraplegia) and with respect to FI it did not differ significantly from both other groups. In order to control for the potential effect of level of activity (leisure vs competitive), the same procedure was performed only with the athletic subjects revealing similar findings $(\mathrm{F}[2,38]=12.1, P=0.0001)$ with sig- nificant differences $(P<0.05)$ between the three groups. Table 4 describes results of the 1-Way ANOVA and post hoc tests for the whole sample and the competitive athletes separately.

Means and SD of each class included in the sample are demonstrated in Table 5. It must be noticed, however, that in the half point classes only very few athletes were represented and generalization of results to these classes should be avoided. This distribution resulted from the consideration of the half point classes as borderline cases according to IWBF manual ${ }^{7}$ and thus, suggested the use of non-parametric statistics in this study. In order to get a further impression of the effect of level of functional ability on power output, a Kruskal Wallis 1-Way ANOVA was 
Table 5 Means and SD of anaerobic and aerobic PO values in each of the integrated functional classes

\begin{tabular}{|c|c|c|c|c|c|c|c|c|}
\hline $\begin{array}{l}\text { Class } \\
N\end{array}$ & $\begin{array}{c}1 \\
13\end{array}$ & $\begin{array}{c}1.5 \\
2\end{array}$ & $\begin{array}{l}2 \\
13\end{array}$ & $\begin{array}{c}2.5 \\
1\end{array}$ & $\begin{array}{l}3 \\
4\end{array}$ & $\begin{array}{c}3.5 \\
1\end{array}$ & $\begin{array}{l}4 \\
6\end{array}$ & $\begin{array}{r}4.5 \\
10\end{array}$ \\
\hline MP & $\begin{array}{l}266.48 \\
(83.09)\end{array}$ & $\begin{array}{l}328.15 \\
(35.71)\end{array}$ & $\begin{array}{l}315.22 \\
(16.93)\end{array}$ & 279.7 & $\begin{array}{l}316.45 \\
(13.63)\end{array}$ & 352.5 & $\begin{array}{l}392.12 \\
(83.08)\end{array}$ & $\begin{array}{c}456.26 \\
(102.36)\end{array}$ \\
\hline PP & $\begin{array}{l}337.94 \\
(93.36)\end{array}$ & $\begin{array}{l}420.55 \\
(45.75)\end{array}$ & $\begin{array}{l}416.76 \\
(91.17)\end{array}$ & 429.9 & $\begin{array}{l}383.45 \\
(33.45)\end{array}$ & 409.4 & $\begin{array}{l}472.42 \\
(81.13)\end{array}$ & $\begin{array}{c}557.78 \\
(111.27)\end{array}$ \\
\hline POaer & $\begin{array}{c}90.3 \\
(24.87)\end{array}$ & $\begin{array}{c}131.33 \\
(10.97)\end{array}$ & $\begin{array}{c}106.71 \\
(34.24)\end{array}$ & 52.6 & $\begin{array}{l}124.62 \\
(24.98)\end{array}$ & 188.0 & $\begin{array}{c}133.65 \\
(20.99)\end{array}$ & $\begin{array}{r}173.50 \\
(15.09)\end{array}$ \\
\hline
\end{tabular}

Table 6 Results of 1-Way Kruskal Wallis ANOVA by functional classification (Class: 1 to 4.5 ) with posterior Tukey HSD Analysis between classes

\begin{tabular}{|c|c|c|c|c|}
\hline Variable & $\begin{array}{c}n \text { of } \\
\text { subjects }\end{array}$ & $F$ & Significance & $\begin{array}{c}\text { Difference } \\
\text { between } \\
\text { classes } \\
(P<0.005)\end{array}$ \\
\hline MP & 50 & 5.30 & 0.0002 & $1<4,4.5$ \\
\hline PP & 50 & 5.01 & 0.0003 & $1,2<4.5$ \\
\hline FI & 50 & 2.07 & 0.683 & n.s. \\
\hline POaer & 50 & 5.40 & 0.0002 & $1,2<4.5$ \\
\hline
\end{tabular}

computed on the PO variables by classification. A post hoc Tukey range HSD was applied, if significant effects were found among the classification groups (Table 6).

The relationships between the functional level (based on integrated classification model) and PO results has been described by means of linear regression analysis deriving the following models: (a) $\mathrm{MP}=48.80 *$ Classification $+214.74 \quad(R=0.65,48$ Degrees of Freedom); (b) $\mathrm{PP}=52.7^{*}$ Classification + $292.72(R=0.62,48 \mathrm{DF}) ; \quad(\mathrm{c})$ POaer $=15.47^{*}$ Classification $+77.89(R=0.55,48 \mathrm{DF})$.

The results of the regression analysis demonstrate that classification of the sample included in this study accounts for 42 and $38 \%$ of the variance in anaerobic peak and mean power respectively, and $30 \%$ of the variance in aerobic power output. Figure 2 presents a scatter diagram and a linear regression describing the relationship of classification and $\mathrm{MP}$.

Of particular interest are the interrelationships between aerobic and anaerobic variables. Very high correlation coefficients were observed between anaerobic MP and PP values $(r=0.93)$. A significant moderate to good correlation was also observed between MP and POaer $(r=0.62)$. Figure 3 shows the relationship between MP and POaer.

\section{Discussion}

In this study a group or 50 individuals with lower limb impairments of various medical etiologies were subjected to aerobic and anaerobic testing. The results were adjusted for age by means of ANCOVA. Hereby, the relationship of participation in competitive vs leisure sport activity as well as the relationship of

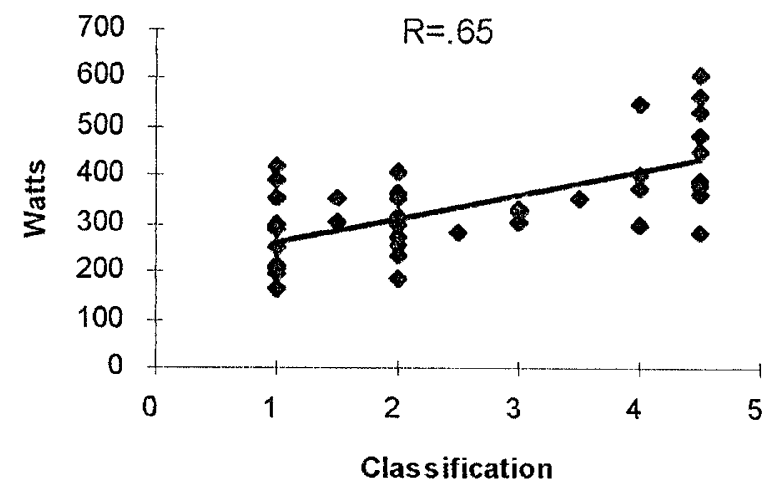

Figure 2 MP by functional classification

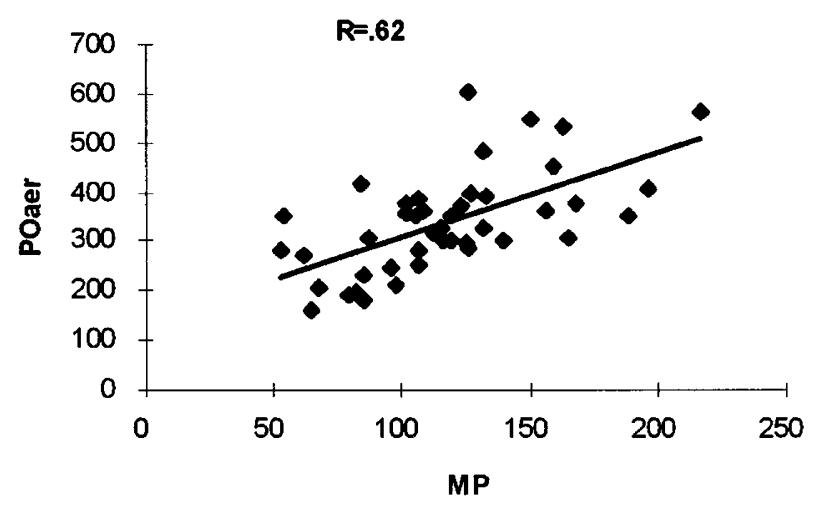

Figure 3 POaer by MP

impairment and functional ability with performance in the tests could be determined.

\section{Relationship of performance and activity intensity}

Participation in physical activity and sports had a significant relationship $(P=0.00)$ with all variables analyzed excluding HR. Maximal HR does not reflect by itself physical fitness and is dependent on age and impairment (particularly in individuals with h.l. paraplegia due to damage to the autonomic nervous system). As expected, all variables which were included as measures of aerobic and anaerobic fitness indicated 
a significant advantage in the individuals who participate regularly in competitive physical activity compared with individuals who participate in physical activity only as a leisure time activity on an irregular basis. These findings concern only groups $a$ and $b$ of individuals with high and low level paraplegia since the other impairment groups in the present study did not include leisure athletes. Our finding is consistent with numerous studies performed with able-bodied individuals, (for review see: ${ }^{24}$ ) as well as with individuals who have lower limb impairments, particularly with respect to the aerobic variables. 5,30,31 Findings concerning the aerobic component of physical fitness were usually measured showing difference in $\mathrm{VO}_{2}$ peak and derived from cross sectional studies $^{12,15}$ as well as from longitudinal studies. ${ }^{32}$ Our analysis did not include VO2peak, but rather POaer and showed a similar trend. ${ }^{33}$ An important finding of this study concerns the relationship of participation intensity and anaerobic fitness variables of individuals with lower limb impairments. The significant difference in favor of the competitively practicing athletes is particularly noticeable in Table 2, showing that the competitively active individuals in group a (with h.l. paraplegia) had almost reached or even exceeded (in POaer and MP) values of individuals in group b who only participated in leisure activities. Previous studies ${ }^{15,19}$ have established the relationships of anaerobic capacity and every-day tasks of wheelchair users ( $r$ ranging $0.50-0.75$ ). It can thus be concluded that individuals with lower-limb impairments who participate in competitive sports may experience an improved function in every-day tasks that usually demand anaerobic resources.

\section{Relationship of performance and age}

The results of the ANCOVA performed on our sample support the generally accepted relationship of HRmax with age. ${ }^{34}$ Aging processes including decrease of HRmax, Stroke Volume and blood flow to the active muscle have been reported, ${ }^{35}$ leading, to a decrease of aerobic capacity at a rate of $10 \%$ per decade. However, adherence to vigorous aerobic training decreases this rate to only $1-2 \%$ per decade. ${ }^{34}$ The significant effect of age on POaer obtained in our sample is in accordance with the reduction in aerobic power observed among non-trained individuals. Recent investigations $^{36-38}$ suggested a similar or even faster rate of decrease in anaerobic power due to reduction in muscle mass, and a shift towards the ST muscle fibers with age. It seems, though, that as in the case of aerobic power, vigorous training may reduce this rate to almost zero. ${ }^{39}$ In the present investigation no relationship was found between age and any of the anaerobic PO variables. It may be speculated that since most of the athletes with lower limb impairments are engaged in rather power/skill (tennis, table tennis, volleyball, weight-lifting) or intermediate (basketball) type activities, athletes have benefited more from the anaerobic effect of their training than from the aerobic component.

\section{Relationship of performance and impairment i.e. functional classification}

The data presented in Tables 3-5 and in Figure 1 demonstrates a trend of increasing performance capacity with decreased impairment in all power output variables. Individuals with lower limb amputations had the best, while those with h.l. paraplegia the lowest achievements. The non-existent or poor stability of the trunk has been attributed as a possible reason for latter functional inferiority. ${ }^{14}$ Previous studies utilizing armcranking ergometry have demonstrated significant difference in aerobic performance $\left(\mathrm{VO}_{2}\right.$ peak and POaer) between individuals with amputation and individuals with Spinal Cord Injury $\left(\mathrm{SCI}^{40}\right)$ as well as between athletes with h.l. paraplegia (group a in our study) and athletes with lower level paraplegia. ${ }^{4}$ Similar results have been demonstrated in a recent study of 52 elite wheelchair basketball players ${ }^{22}$ utilizing treadmill ergometry (with a wheelchair tied to a pully system) and field performance tests. In another study utilizing the latter system of treadmill ergometry with 44 male subjects with SCI, Janssen and associates ${ }^{14}$ revealed significant differences in $\mathrm{VO}_{2}$ peak between individuals with h.l. paraplegia, who were classified as Class II according to International Stoke Mandeville Games Federation (ISMGF) classification system and individuals with lower level impairments classified as class IV under the same system. $\mathrm{VO}_{2}$ peak in the same task, anaerobic MP during a simulated wheelchair propulsion task and isometric maximal force on the handrims did not differ significantly among individuals with h.l. and 1.1. impairments. The latter findings were repeated in a study of Dallmeijer et $a l^{13}$ with 27 individuals with SCI. The lack of significant differences between aerobic performance of ISMGF and IWBF classes (II - V and I-IV respectively) reported in these studies as well as similar results obtained in performance tests $22,41,42$ support a view of reducing the number of classes. The results obtained in the present study reveal nonsignificant differences among individuals with spinal cord and polio lesions with respect to their aerobic capacity. Significant differences in POaer appear only between the individuals with spinal cord related conditions and individuals with lower limb amputations (Table 4). Vanlandewijck et $a l^{22}$ have speculated that anaerobic power output should be considered as a determining factor for classification in wheelchair sports. This hypothesis has been confirmed in part in the present study, revealing significant differences of anaerobic PP between the following groups: (I) high level paraplegia (above T6 complete); (II) low level paraplegia (below T5 complete or equivalent and polio); and (III) lower limb amputations.

These groups were assigned reference values based on the five category scheme established by Astrand and Rohdal ${ }^{43}$ and previously utilized for assessment 
Table 7 PP reference values (in Watts) according to the 3 group scheme suggested in this study

\begin{tabular}{lcccccc}
\hline $\begin{array}{l}\text { Level } \\
\text { category }\end{array}$ & \multicolumn{4}{c}{$\begin{array}{c}\text { Below } \\
\text { Average }\end{array}$} & $\begin{array}{c}\text { Average } \\
\text { Average }\end{array}$ & $\begin{array}{c}\text { Excellent } \\
\text { average }\end{array}$ \\
\hline Group a & $n$ & -3 to -1.8 SD & -1.8 to -0.6 SD & -0.6 to $+0.6 S D$ & +0.6 to +1.8 SD & +1.8 to 3 SD \\
Group b $+\mathrm{c}$ & 12 & $74-176$ & $177-278$ & $279-382$ & $383-484$ & $485-587$ \\
Group d & 12 & $186-279$ & $280-374$ & $375-469$ & $470-563$ & $564-657$ \\
\hline
\end{tabular}

purposes in lower limb impaired individuals with respect to $\mathrm{VO}_{2}$ peak $^{12}$ as well as to Field-Test results. ${ }^{44}$ Table 7 presents the fitness reference values of peak anaerobic power output (PP in Watts) derived from this procedure. The suggestion to use PP in reference tables evaluating physical fitness of individuals with lower limb impairments alongside $\mathrm{VO}_{2}$ peak is based on the following observations (a) most wheelchair sport and every day tasks require substantial anaerobic power. In some sports e.g. in wheelchair basketball and wheelchair tennis, very short duration tasks (i.e. starting and pushing for two-three cycles) are dominating. (b) The relationship of PP with anaerobic MP and aerobic PO are high to moderate $(r=0.93$ and 0.62 respectively and (c) The WAnT requires simple instrumentation that can be installed in every Gym.

\section{A comparative evaluation of power output values}

The results presented in this study concerning POaer show similar values to results reported in previous investigations studying aerobic performance of lower limb individuals. ${ }^{4.45 .46}$ The results concerning PP and MP can be compared to results achieved in a previous study of Hutzler ${ }^{26}$ studying Israeli national team athletes in wheelchair basketball who had reached $393.2 \pm 68.8$ and $324 \pm 55.9$ Watts respectively. These values correspond average values of group II in the present study. These results can further be compared to maximal power outputs of ten Japanese wheelchair basketball players who had been tested by means of a 10 s Force Velocity Test $(\mathrm{X}=351 \pm 104$ Watts: 17$)$, as well as to able-bodied male athletes aged 26-35 who had participated in arm exercise as reported by Inbar, Bar-Or and Skinner. ${ }^{27}$ The average values of the latter subjects were similar to those of the wheelchair athletes in group II and somewhat lower $(18-23 \%)$ than the athletes in group III reported in the present study. The significant relationships observed between anaerobic MP and aerobic POaer seems to be a result of the intermediate aerobic and anaerobic characteristic of wheelchair sports in general and wheelchair basketball in particular.

\section{Summary}

This study included an analysis of results derived from aerobic and anaerobic tests performed with 50 individuals with lower limb impairments. While adjusting results for the effect of age, the importance of regular participation in physical activity and sports as well as certain effects of functional ability on variables of physical fitness in individuals with lower limb impairments have been demonstrated. On the bases of our findings age relates to performance only in the aerobic variables. This seems to to be a result of the specific training in wheelchair sports concentrating on anaerobic performance. Type and level of impairment and functional classification have a moderate relationship with performance. Considering the relationships of power outputs and functional classification obtained in the present study, findings suggest a consequent significant difference only between individuals with amputations and those with spinal cord injuries or polio. A subdivision of paralyzing conditions seems justified only with respect to peak anaerobic power, which is, however, a very important factor in wheelchair sports. A statistical analysis was applied in order to develop a scheme for a differential fitness assessment with respect to anaerobic PP in three groups comprising of (I) high level paraplegia (above T6 complete); (II) low level paraplegia (below T5 complete or equivalent and polio); and (III) lower limb amputations. Reference values for PP in each of these groups have been generated. Caution should still be taken while interpreting our reference values, since several classes (those with half point invervals - Table 4) were represented with a limited number of subjects. Also, it must be noticed that the subjects in this study were involved in several kinds of physical activity. The same analysis needs verification in larger samples of homogenous active or non-active groups. Further research is thus recommended, in order to verify the relationships described in this study. Larger and homogenous groups should be included in order to reveal valid norm tables.

\section{References}

1 Davis GM. Exercise capacity of individuals with paraplegia. Medicine and Science in Sports \& Exercise 1993; 25: 423-432.

2 Shephard RJ. Physical fitness testing of the disabled. Champaign, Ill: Human Kinetics, 1990.

3 Knutsson E, Lewenhaupt-Olsson E, Thorsen M. Physical work capacity and physical conditioning in paraplegic patients. Paraplegia 1973; 11: $205-216$. 
4 Kofsky PR et al. Field testing assessing of physical fitness of disabled adults. European Journal of Applied Physiology 1983; 51: $109-120$.

5 Zwirn LD, Bar-Or O. Responses to exercise of paraplegics who differ in conditioning level. Medicine and Science in Sports and Exercise, 1975; 7: $94-98$.

6 Longmuir PE, Shephard RJ. Refinement of the arm CAFT protocol for assessing aerobic fitness in adults with mobility impairments. Adapted Physical Activity Quarterly 1995; 12: 362 376.

7 International Wheelchair Basketball Federation [IWBF]. Handbook. Available from Phil Craven, Chairman, 1 Medow Close, Shavington Nr. Crewe, Cheshire CW2 5BE, England, 1995.

8 Riding MD. Classification: address to the Paralympic Congress. (report of the second paralympic congress enclosure). Lilihammer, Norway: Royal Norwegian Ministry of Cultural Affairs, 1994.

9 Paralympics Barcelona. General and functional classification guide. Barcelona, Spain. C.O.O.B. '92 S.A. Paralympic Division, 1992.

10 Strohkendl H. The new classification system for wheelchair basketball. In: C. Sherrill (ed). Sport and disabled athletes. 1984 Olympic scientific congress proceedings (Vol. 9, pp 101-112). Champaign, Human Kinetics, 1986.

11 Franklin BA. Exercise testing, training and arm ergometry. Sports Medicine 1985; 2: 100-119.

12 Kofsky PR, Shephard RJ, Davis GM, Jackson RW. Fitness classification tables for lower-limb disabled individuals. In: C Sherrill (ed). Sport and disabled athletes. Human Kinetics Publishers, Champaign, 1986 pp $147-156$.

13 Dallmeijer AJ et al. Anaerobic power output and propulsion technique in spinal cord injured subjects during wheelchair ergometry. Journal of Rehabilitation Research and Development 1994; 31,2; $120-128$.

14 Janssen TW et al. Isometric strength, sprint power and aerobic power in individuals with spinal cord injury. Medicine and Science in Sports and Exercise 1993; 25,7: 863-870.

15 Bar-Or O, Inbar O, Dotan R. Proficiency, speed and endurance test for wheelchair bound. Unpublished paper presented at the international Seminar on motor learning in physical education and sports held at the Wingate Institute, Netanya, Israel, April 1976.

16 Hutzler Y. The relevance of anaerobic power for wheelchair propulsion. In: LHV van der Woude, PJM Meijs \& YA de Boer (eds). Ergonomics of manual wheelchair propulsion, state of the art. Amsterdam: IOS Press, 1993 pp 139-148.

17 Tsukagoshi $\mathrm{K}$ et al. Maximal anaerobic power during maximal arm cranking in wheelchair athletes and non-athletes. 10th ISAPA Oslo, May 22-26, 1995.

18 Coutts KD. Dynamics of wheelchair basketball. Medicine and Science in Sports and Exercise 1992; 24: 231 - 234.

19 Janssen TWJ et al. Physical strain during activities of daily living in spinal cord injured subjects. Paraplegia 1994; 32: $844-859$.

20 Hoffman MD. Cardiorespiratory fitness and training in quadriplegics and paraplegics. Sports Medicine 1986; 3: $312-$ 330.

21 Bar-Or O, Geron E. Physiological and psychological effects on paraplegics of a sports rehabilitation program - a longitudinal approach. Paper presented at the 8th International Congress on Physical Therapy. Tel Aviv, Israel, 28 May-2 June, 1978.

22 Vanlandewijk Y, Spaepen AJ, Lysens RJ. Relationship between the level of impairment and sports performance in elite wheelchair-basketball athletes. Adapted Physical Activity Quarterly 1995; 12: $139-150$.

23 Sawka MN et al. Wheelchair exercise performance in the young, aged and elderly. Journal of Applied Physiology 1981; 50: 824828 .

24 Wilmore JH, Costill DL. Training for sport and activity: The physiological basis of the conditioning process (3rd Ed). Champaign, Ill: Human Kinetics, 1993.
25 Bar-Or O. The Wingate anaerobic test. An update on methodolgy, reliability and validity. Sports Medicine 1987; 4: $381-397$.

26 Hutzler Y. Physical performance of elite wheelchair basketball players in armcranking ergometry and in selected wheeling tasks. Paraplegia 1993; 31: 255-261.

27 Inbar O, Bar-Or O, Skinner AS. The wingate anaerobic test: development, characteristics and application. Champaign, Ill: Human Kinetics, 1996.

28 Bar-Or O, Zwirn L. Maximal oxygen consumption test during arm exercise-reliability and validity. Journal of Applied Physiology, 1975; 38: 424-426.

29 Tirosh E, Bar-Or O, Rosenbaum P. New muscle power test in neuromuscular disease: Feasibility and reliability. American Journal of Diseased Child, 1990; 144: 1083-1087.

30 Cameron BJ, Ward GR, Wicks JR. Relationship of type of training to maximal oxygen uptake and upper limb strength in male paraplegic athletes. Medicine and Science in Sports 1978; 9: 58.

31 Davis GM, Shephard RJ. Cardiorespiratory fitness in highly active versus less active paraplegics. Journal of Applied Physiology 1987; 56: 90-96.

32 Miles DS. Pulmunary function changes in wheelchair athletes subsequent to exercise training. Ergonomics 1982; 25: 239-246.

33 Dreisinger TE. Wheelchair exercise - A review. Paraplegia 1984 20: $20-34$.

34 Wilmore JH, Costill DL. Physiology of Sport and Exercise. Champaign, Ill: Human Kinetics, 1994.

35 Wahren L, Saltin B, Jorfeldt L, Pernow B. Influence of age on the local circulatory adaptation to leg exercise. Scandinavian Journal of Clinical Laboratory Investigation 1974; 33: 79-86.

36 Chamari K, Ahmaidi S, Fabre C, Masse-Biron J. Anaerobic and aerobic peak power output and the force-velocity relationship in endurance-trained athletes: effects of aging.

37 Grassi B, Cerretelli P, Narici M, Marconi C. Peak anaerobic power in master athletes. European Journal of Applied Physiology and Occupational Physiology 1991; 62: $394-399$.

38 Meltzer DE. Age dependence of olympic weightlifting ability. Medicine and Science in Sports and Exercise 1994; 26: $1053-$ 1067.

39 Lexell J, Taylor CC, Sjpstrom M. What is the cause of the aging atrophy? Total number, size and proportion of different fiber types studied in whole vastus lateralis muscle from 15- to 83-yearold men. Journal of Neurological Science 1988; 84: 275-294.

40 Grimby G. Aerobic capacity, muscle strength and fiber composition in young paraplegics. In $\mathrm{H}$ Natvig (ed). First international medical congress on sports for the disabled. Oslo: Royal Ministry for church and education 1980

41 Brasile FM. Wheelchair basketball skills proficiencies versus disability classification. Adapted Physical Activity Quarterly 1986; 3: $6-13$

42 Brasile FM. Performance evaluation of wheelchair athletes. Adapted Physical Activity Quarterly 1990; 7: 289-297.

43 Astrand PO, Rodahl K. Textbook of work physiology (2nd ed). New York: McGraw-Hill Book Company, 1986.

44 Rhodes EC, McKenzie DC, Coutts KD, Rogers AR. A field test for the prediction of aerobic capacity in male paraplegics and quadraplegics. Canadian Journal of Applied Sport Sciences 1981; 6: $182-186$

45 Hjeltnes N. Oxygen uptake and cardiac output in graded arm exercise in paraplegics with low level spinal lesions. Scandinavian Journal of Rehabilitation Medicine 1977; 9: 107-113.

46 Hullemann KO et al. Spiroergometric and telemetric investigations during the XXI International Stoke Mandeville Games, 1972 in Heidelberg. Paraplegia 1975; 13: $109-123$. 